\title{
A Disposable Microfluidic Device with a Screen Printed Electrode for Mimicking Phase II Metabolism
}

\author{
Rafaela Vasiliadou ${ }^{1, *}$, Mohammad Mehdi Nasr Esfahani ${ }^{2}$, Nathan J. Brown ${ }^{2}$ and \\ Kevin J. Welham ${ }^{1}$ \\ 1 Department of Chemistry, University of Hull, Cottingham Road, Hull HU6 7RX, UK; k.j.welham@hull.ac.uk \\ 2 Department of Engineering, University of Hull, Cottingham Road, Hull HU6 7RX, UK; \\ m.m.n.esfahani@gmail.com (M.M.N.E.); N.J.Brown@hull.ac.uk (N.B.) \\ * Correspondence: R.Vasiliadou@hull.ac.uk or vasiliadourafaela@hotmail.com
}

Academic Editors: Jesus Iniesta Valcarcel and Craig E. Banks

Received: 9 May 2016; Accepted: 25 August 2016; Published: 2 September 2016

\begin{abstract}
Human metabolism is investigated using several in vitro methods. However, the current methodologies are often expensive, tedious and complicated. Over the last decade, the combination of electrochemistry (EC) with mass spectrometry (MS) has a simpler and a cheaper alternative to mimic the human metabolism. This paper describes the development of a disposable microfluidic device with a screen-printed electrode (SPE) for monitoring phase II GSH reactions. The proposed chip has the potential to be used as a primary screening tool, thus complementing the current in vitro methods.
\end{abstract}

Keywords: metabolism; electrochemistry; screen-printed electrodes; mass spectrometry

\section{Introduction}

Metabolism is a physiological process occurring in the liver, which enhances the elimination of both endogenous and exogenous compounds. Metabolites are formed during phase I and phase II metabolic reactions [1,2]. During natural conditions, phase I metabolites conjugate with glutathione (GSH) - a reaction catalysed by glutathione S-transferases (GSTs) - and are detoxified (phase II reactions) [3-5]. However, during phase I reactions, reactive metabolites can form, some of which are toxic to DNA and proteins [6,7]. Currently, in vitro methodologies are expensive and involve lengthy experimental procedures [8].

Direct electrochemistry in electrochemical flow cells can mimic the catalytic activity of CYP 450 in a cost effective manner [9]. In this technique, metabolites are synthesized electrochemically on the working electrode and detected by mass spectrometry (MS) either intact or as phase II GSH-adducts [10], depending on the application. Acetaminophen (APAP) and dopamine (DOPA) are electroactive compounds with well-known metabolic routes that are widely used in the field [11-13]. In 1989, Getek et al. generated and detected GSH conjugates of APAP by coupling online an electrochemical flow cell with a thermospray mass spectrometer. The reactive metabolite $N$-acetyl-p-benzoquinone imine (NAPQI) was formed in the electrochemical cell and reacted subsequently with GSH in a mixing tee [14]. Lohhmann et al. [15], used a commercially available cell equipped with a glassy carbon working electrode, a $\mathrm{Pd} / \mathrm{H}_{2}$ reference electrode and a Pd counter electrode. The isomeric adducts of APAP were obtained and detected by liquid chromatography (LC)/mass spectrometry (MS). More recently, a miniaturized electrochemical cell with high conversional rates was developed by Van den Brink et al. [16]. The microfluidic device had a dual application, either the generation of short lived metabolites or the formation of GSH-adduct via the addition of a T-piece on the effluent of chip. However, flow cells and glass microfluidics are fabricated from expensive materials and require tedious cleaning methods for their reuse. A cost effective polymer chip for electrochemical tagging was fabricated by Roussel et al. [17]. The electrospray emitter was 
developed with a microchannel and an integrated carbon electrode. The electrode surface-to-volume ratio was $50 \mathrm{~m}^{-1}$ providing an efficient electrolytic cell for both electrochemical reactions and mass spectrometric detections. Screen-printed electrodes (SPEs) are commercially available disposable sensors, which can also be readily custom-made. The fabrication process relies on the screen printing technique, involving the deposition of ink or paste onto a ceramic, glass, or plastic substrate [18-21]. SPEs are becoming widely applied in the field of electrochemistry due to their simplicity, portability, low cost, mass production, and miniaturized format [21].

Kauffmann et al. [21] used a carbon SPE instead of a conventional flow cell for electrochemically mimicking the metabolism of APAP. The sensor included all the required electrodes-including the working, reference, and counter electrodes-resulting in an alternative miniaturized cell. The reactive metabolite of APAP, the NAPQI, was generated on the working area of the SPE in the presence of excess GSH concentration. NAPQI was covalently bonded with GSH, leading to the formation of an APAP-GSH phase II adduct. The resulting phase II adduct was detected offline by liquid chromatography (LC)/ESI-MS. Thus, the development of a primary screening tool with an SPE can complement the in vitro methods, saving both time and cost. In the present study, we describe the integration of a commercially available sensor (DS-110: DropSens, Oviedo, Spain) with a serpentine reaction channel into a disposable polymeric chip, for mimicking phase II GSH reactions. A cheaper alternative towards the existing flow cells and glass microfluidic chips without the need of any tedious cleaning processes. In addition, the electrochemical step is separated from the ionization process, as seen in the previous polymeric design [17], ensuring that the generated metabolites are electrochemically driven and not the result of ionization. DOPA was used as a probe compound for monitoring the phase II GSH reactions. According to the literature, dopaminoquinone is the reactive intermediate of DOPA and probably the causal agent of Parkinson's disease [22].

\section{Experimental Section}

\subsection{Chemical Reagents}

DOPA and GSH were purchased from Sigma Aldrich (Gillingham, UK). APAP was obtained by Alfa Aesar (Heysham, UK). Buffers of different $\mathrm{pH}$ values were prepared using ammonium acetate (Fisher scientific, Loughborough, UK), sodium phosphate dibasic (Sigma Aldrich), and potassium phosphate monobasic (Sigma Aldrich). The reagents were used as received without any additional purification. All solutions were degassed with pure nitrogen (99.9\%) for $15 \mathrm{~min}$ prior to electrochemical measurements. The water was deionised using an Elgastat prima 3 reverse osmosis unit (Elga Ltd., High Wycombe, UK).

\subsection{Instrumentation}

The electrochemical measurements were recorded using an SP-50 potentiostat (Bio-Logic, Claix, France) and a PalmSens 3 potentiostat (Alvatek, Tetbury, UK). Metabolites were identified by ESI/MS using a LCQ Classic ion trap mass spectrometer (Thermo Scientific, Hemel Hempstead, UK). A syringe pump MD-1002 pursued from Basi (West Lafagette, IN, USA) was used to introduce sample and GSH solutions into the chip.

\subsection{Screen-Printed Electrodes (SPEs)}

Unmodified SPEs (DropSens) were used for the mimicry of phase II metabolism. A three electrode configuration (Figure 1), composed of a carbon working (4 mm diameter) electrode, a carbon counter electrode, and a silver reference electrode. The dimensions of the sensor were $3.4 \mathrm{~cm} \times 1.0 \mathrm{~cm} \times 0.05 \mathrm{~cm}$ (length $\times$ width $\times$ height). An edge connector DRP-DSC (DropSens) served as an interface between the SPE and potentiostat. 


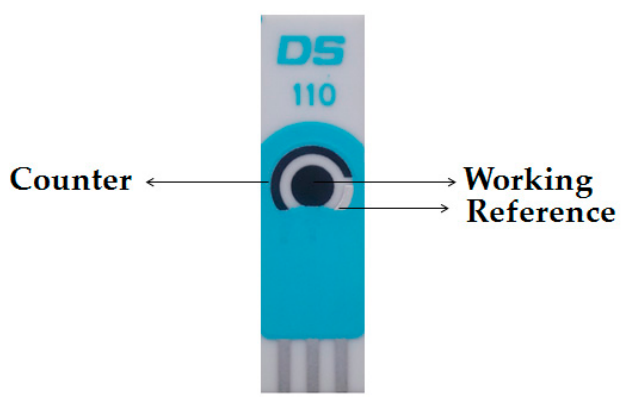

Figure 1. Unmodified screen-printed electrode (SPE) with a three electrode configuration.

\subsection{Microfluidic Device with an SPE}

An SPE was integrated with a serpentine reaction channel into a polymeric chip for monitoring phase II metabolism. The working principle involved the electrochemical generation of the phase I intermediates within the SPE cell and their subsequent conjugation with GSH in a serpentine reaction channel.

\subsubsection{Time of Electrolysis in the SPE Cell}

Investigations on SPEs suggested that $0.5 \mathrm{~min}$ of control potential electrolysis (CPE) was sufficient for GSH-adduct detection in MS [21]. Thus equal or longer durations of electrolysis are required within the SPE cell. Considering the delicate structure of the integrated chip and the capabilities in MS, the selected flow rate range was from $2.5 \mu \mathrm{L} \cdot \mathrm{min}^{-1}$ to $50 \mu \mathrm{L} \cdot \mathrm{min}^{-1}$. The volume of SPE cell was $32 \mu \mathrm{L}$ to ensure longer durations of electrolysis $(t>0.5 \mathrm{~min})$ at the selected flow rate range, Table 1.

Table 1. Effect of flow rate in metabolic synthesis and GSH conjugation.

\begin{tabular}{cccc}
\hline $\begin{array}{c}\text { Flow Rate } \\
\left(\boldsymbol{\mu L} \cdot \mathbf{m i n}^{-1}\right)\end{array}$ & $\begin{array}{c}\text { Time of Electrolysis } \\
(\mathbf{m i n})\end{array}$ & $\begin{array}{c}\text { Combined Flow Rate } \\
\left(\mu \mathbf{L} \cdot \mathbf{m i n}^{-\mathbf{1}}\right)\end{array}$ & $\begin{array}{c}\text { Time of GSH } \\
\text { Conjugation }(\mathbf{m i n})\end{array}$ \\
\hline 2.5 & 12.8 & 5.0 & 4.8 \\
5 & 6.4 & 10 & 2.4 \\
10 & 3.2 & 20 & 1.2 \\
20 & 1.6 & 40 & 0.6 \\
30 & 1.1 & 60 & 0.4 \\
60 & 0.6 & 100 & 0.2 \\
\hline
\end{tabular}

\subsubsection{Time of GSH Conjugation in a Serpentine Channel}

In a serpentine reaction channel, the laminar flows of test sample and GSH are expected to diffuse and then to react covalently. The width of the serpentine channel is a key parameter for determining the time of diffusion mixing. As shown in Equation (1), a width of $0.01 \mathrm{~cm}$, at a diffusion coefficient of $3.0 \times 10^{-6} \mathrm{~cm}^{2} / \mathrm{s}$, provided a diffusion mixing of $0.28 \mathrm{~min}$. The calculated times for GSH conjugation, at the combined flow rate range of $5 \mu \mathrm{L} \cdot \mathrm{min}^{-1}$ to $100 \mu \mathrm{L} \cdot \mathrm{min}^{-1}$, are shown in Table 1 . At all flow rates, the duration of conjugation is longer or close to the time required for diffusion mixing:

$$
t=\frac{(\text { width })^{2}}{2 x(\text { diffusion coefficient })}
$$

\subsubsection{Fabrication of Chip}

The chip was fabricated from three polycarbonate wafers of $3.3 \mathrm{~cm} \times 1.7 \mathrm{~cm}$ (length $\times$ width), bonded together with silicone and double adhesive tape (Figure 2). A $32 \mu \mathrm{L}$ SPE cell, a $20 \mu \mathrm{L}$ serpentine reaction channel of $120 \mathrm{~mm} \times 0.01 \mathrm{~cm} \times 20 \mu \mathrm{m}$ (length $\times$ width $\times$ depth) and a side channel of 
$80 \mathrm{~mm} \times 0.04 \mathrm{~cm} \times 20 \mu \mathrm{m}$ (length $\times$ width $\times$ depth) were drilled into the middle layer (Figure 2B) by a computer numerical control (CNC) machine (Daltron, New Hampshire, NH, USA). The inlets and outlet were drilled in wafer (Figure 2A), and wafer (Figure 2C) served as a base for the chip. The full design of the proposed chip is shown in Figure 2D.
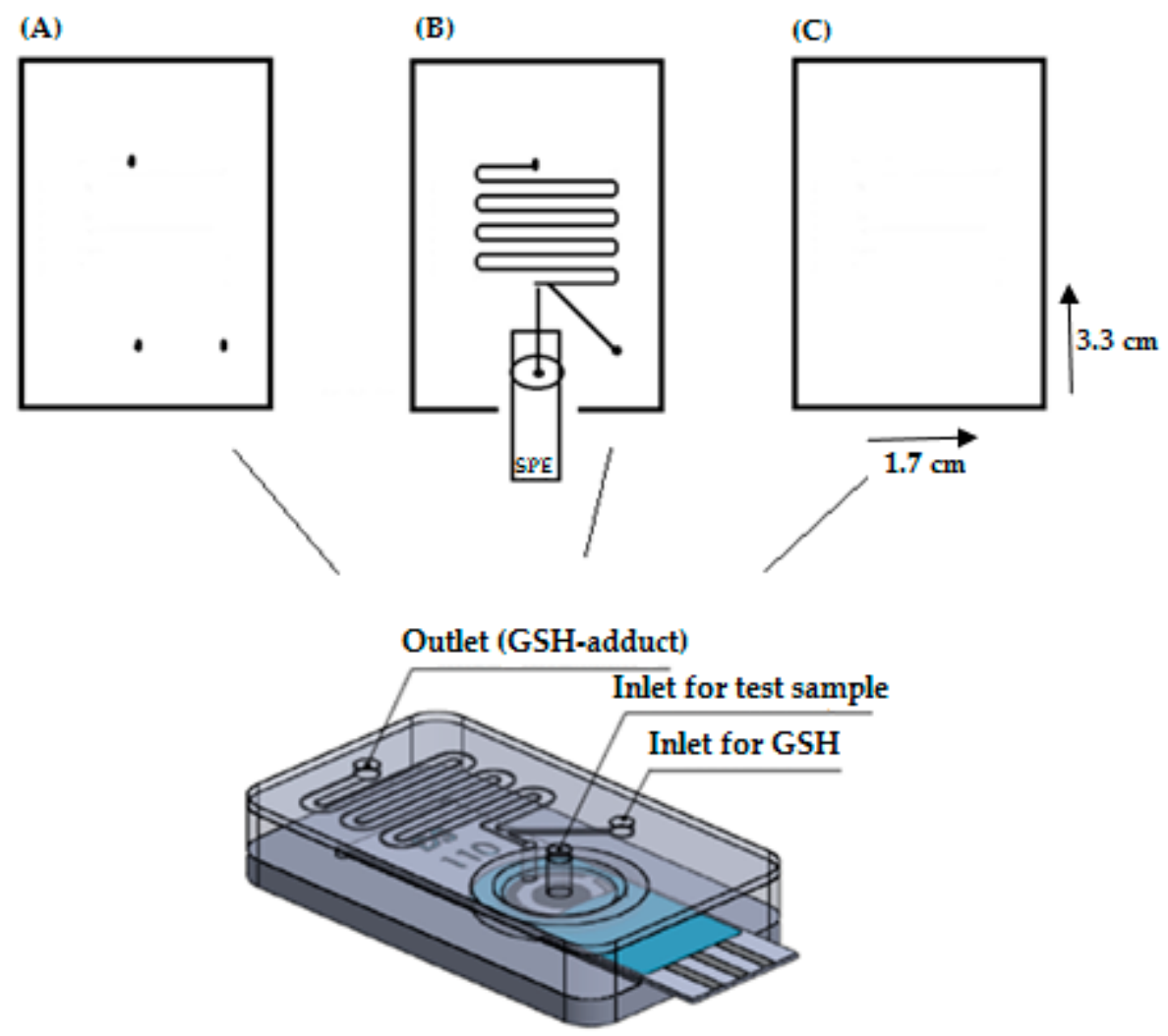

(D)

Figure 2. Fabrication process. (A) Top wafer with inlets and outlet; (B) middle wafer containing the $32 \mu \mathrm{L}$ SPE cell and $20 \mu \mathrm{L}$ serpentine reaction channel; (C) base layer and (D) full design of the chip.

\subsection{Optimization of SPES}

Prior to microfluidic investigations, the conditions for DOPA metabolism were optimized on bare SPEs. A new SPE was used for each experiment, considering the disposable nature of the sensor. For both kinetic and synthetic applications, $50 \mu \mathrm{L}$ of sample solution were loaded into the three electrode configuration. Oxidation products were subsequently detected by offline ESI/MS.

\subsection{Chip/ESI-MS}

The integrated chip was coupled online to ESI/MS via transfer capillaries (Figure 3). DOPA $\left(2.5 \times 10^{-5} \mathrm{M}\right)$ in $0.1 \mathrm{M}$ ammonium acetate was infused into the SPE cell at a constant flow rate of $5 \mu \mathrm{L} \cdot \mathrm{min}^{-1}$ and electrolyzed for $6.4 \mathrm{~min}$. GSH $\left(5 \times 10^{-5} \mathrm{M}\right)$ in $0.1 \mathrm{M}$ of ammonium acetate was also infused at the same flow rate towards the serpentine channel and conjugated covalently with the oxidation products for $2.4 \mathrm{~min}$. It should be emphasized that a new chip was used for each electrolysis. 


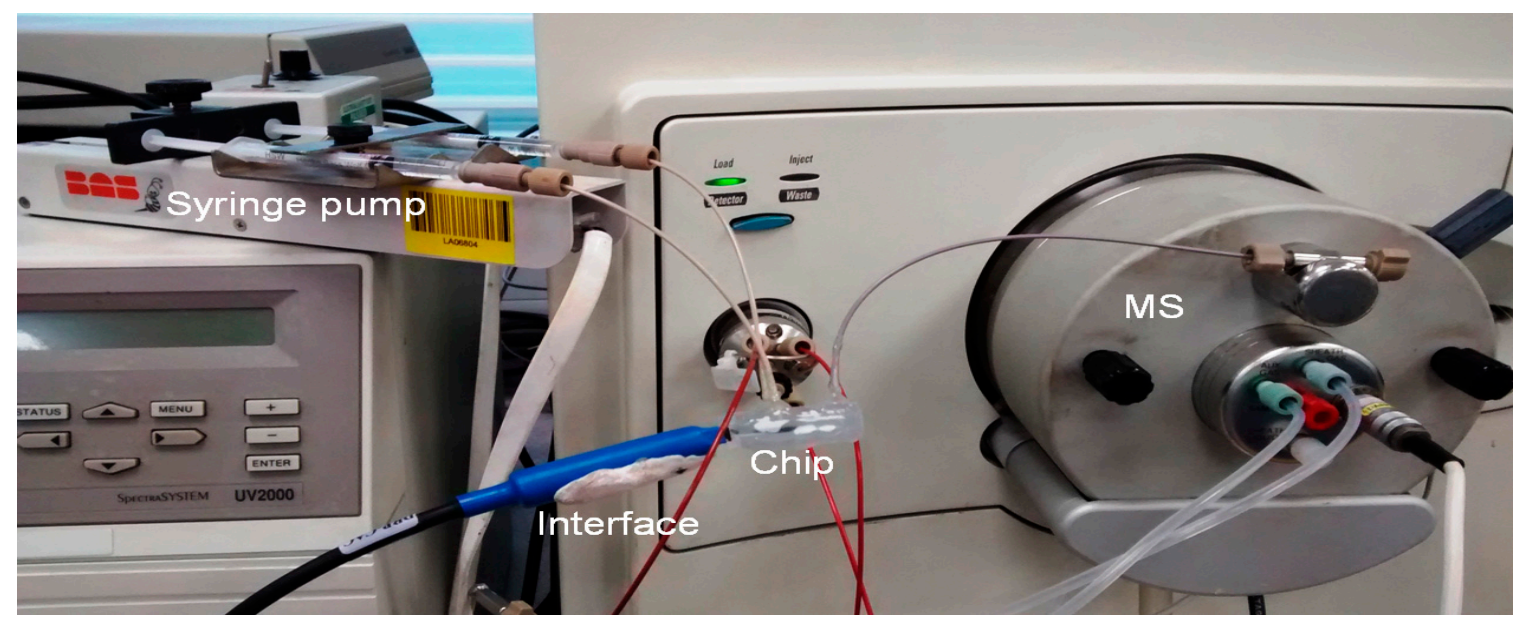

Figure 3. Online coupling of chip with electrospray ionization/mass spectrometry (ESI/MS).

\section{Validation of SPEs}

\subsection{Electrochemical Behavior of DOPA}

Cyclic voltammetry was used to study the electrochemical behaviour of DOPA on an SPE. The voltammetric response of DOPA $\left(2.5 \times 10^{-5} \mathrm{M}\right)$ in $0.1 \mathrm{M}$ phosphate buffer $(\mathrm{pH} 5)$ was recorded over the potential range of $0.3-0.6 \mathrm{~V}$ and at $0.155 \mathrm{~V} \cdot \mathrm{s}^{-1}$ scan rates. A redox pair was obtained with an oxidative peak at $0.128 \mathrm{~V}$ and a reductive peak at $-0.08 \mathrm{~V}$ (Figure 4 ). The separation peak potential $(\Delta \mathrm{E} \varrho)$ was found to be $0.208 \mathrm{~V}$, indicating a quasi-reversible process [23].

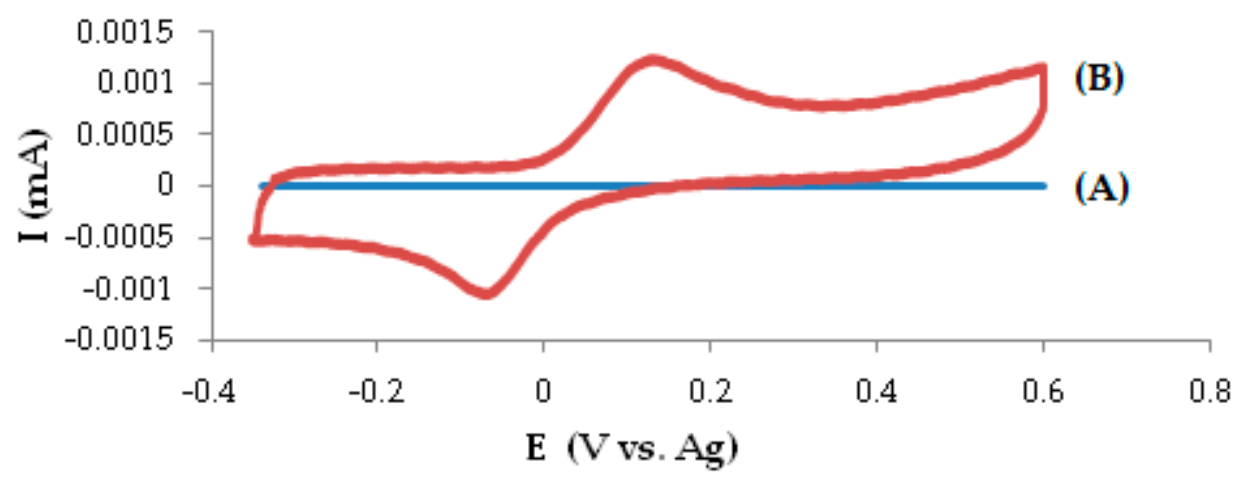

Figure 4. Cyclic Voltammograms of (A) Blank electrolyte solution, $(\mathbf{B})$ DOPA $\left(2.5 \times 10^{-5} \mathrm{M}\right)$.

\subsection{Effect of $p H$}

Cyclic voltammograms of DOPA $\left(2.5 \times 10^{-5} \mathrm{M}\right)$ were recorded in different $\mathrm{pH}$ values $(0.1 \mathrm{M}$ phosphate buffers at $\mathrm{pH} 1,2,3,4,5,6,7,8)$ at $0.1 \mathrm{~V} \cdot \mathrm{s}^{-1}$ scan rates.

\subsubsection{Participation of Protons}

A linear relationship was obtained between the anode potential $\left(\mathrm{E}_{\mathrm{pa}}\right)$ and $\mathrm{pH}$, suggesting the participation of protons during the electrochemical process (Figure 5). The anode potential shifted to more negative values as $\mathrm{pH}$ increased. The obtained slope $0.0514 \mathrm{~V} \cdot \mathrm{pH}^{-1}$ was close to the Nernestian slope of $0.059 \mathrm{~V} \cdot \mathrm{pH}^{-1}$ [24], implying the involvement of the same number of protons and electrons. 


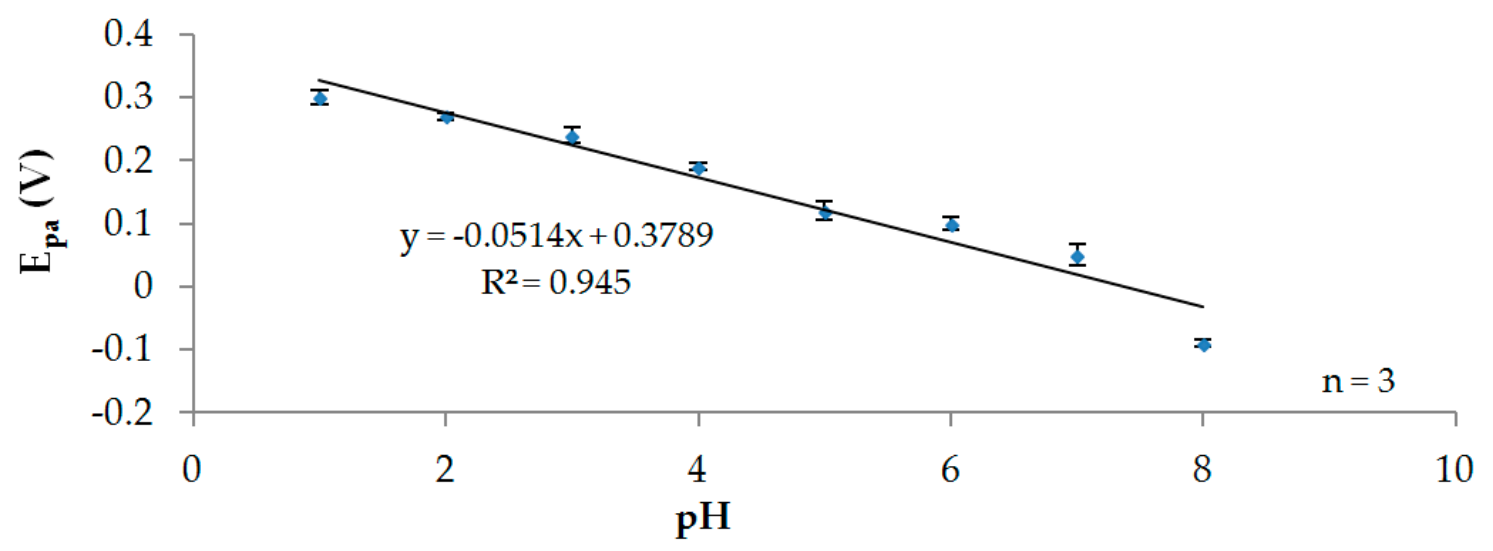

Figure 5. Dependence of anode potential $\left(\mathrm{E}_{\mathrm{pa}}\right)$ with $\mathrm{pH}$. Not visible error bars: when the symbol size is larger than the error bar.

\subsubsection{Stability Studies}

A peak current ratio $\left(\mathrm{I}_{\mathrm{pa}} / \mathrm{I}_{\mathrm{pc}}\right)$ close to unity [25] is considered as a criterion of product stability. The anode $\left(\mathrm{I}_{\mathrm{pa}}\right)$ and cathode $\left(\mathrm{I}_{\mathrm{pc}}\right)$ currents have the same magnitude since the electrogenerated intermediate is not participating in further reactions. As shown in Figure 6, the product was stable over acidic conditions. The highest stability was obtained at $\mathrm{pH} 5$ with an $\mathrm{I}_{\mathrm{pa}} / \mathrm{I}_{\mathrm{pc}}$ of 1.08 . In more alkaline conditions, the $\mathrm{I}_{\mathrm{pa}} / \mathrm{I}_{\mathrm{pc}}$ started to increase, suggesting instability and further reactions with molecules in solutions. At $\mathrm{pH} 8$ the greatest instability was seen with an $\mathrm{I}_{\mathrm{pa}} / \mathrm{I}_{\mathrm{pc}}$ of 3.2.

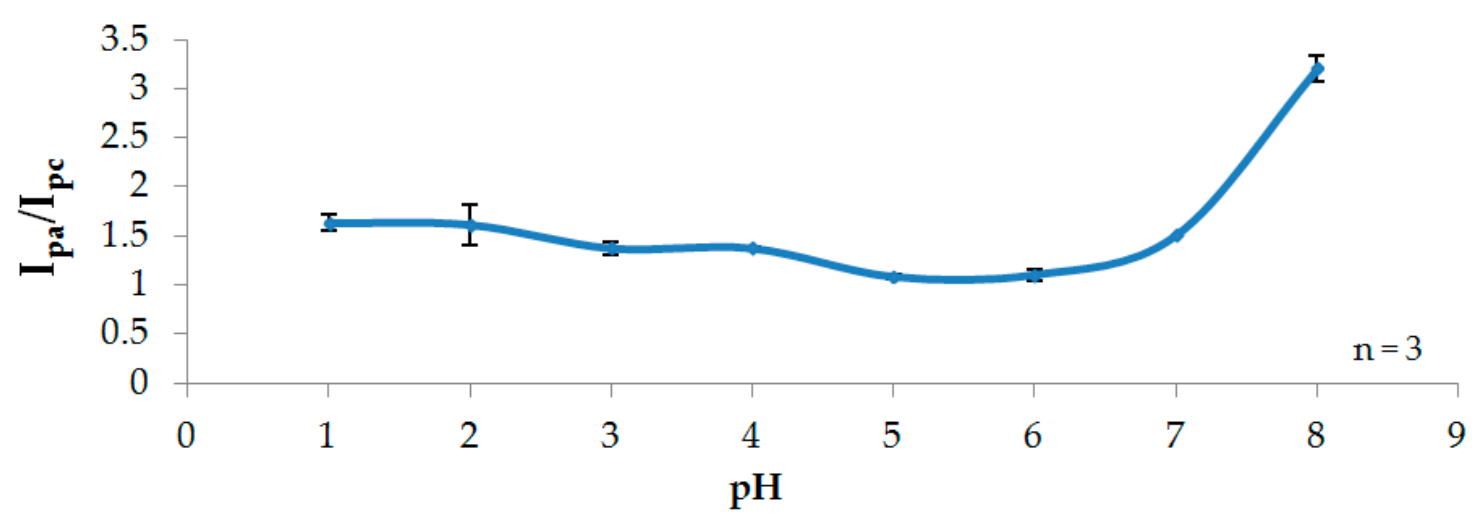

Figure 6. Product stability as a function of $\mathrm{pH}$. Not visible error bars: when the symbol size is larger than the error bar.

\subsubsection{Current}

The concentration of the electrogenerated product is directly proportional to the obtained current [26]. Herein, the highest signals for both $\mathrm{I}_{\mathrm{pa}}$ and $\mathrm{I}_{\mathrm{pc}}$ were observed at $\mathrm{pH} 4$ (Figure 7). For $\mathrm{pH}$ values of 1-3 and 5-8, signals were low, implying less product formation. The obtained peak currents were in good agreement with the stability studies since at $\mathrm{pH} 8$ the product was unstable and lower currents were generated.

\subsection{Effect of Scan Rate}

Useful information regarding the electrochemical reaction mechanisms can be acquired from the potential scan rate. Therefore, the electrochemical response of DOPA $\left(2.5 \times 10^{-5} \mathrm{M}\right)$ in $0.1 \mathrm{M}$ phosphate buffer ( $\mathrm{pH}$ ) was investigated at different scan rates from $0.02 \mathrm{~V} \cdot \mathrm{s}^{-1}$ to $0.155 \mathrm{~V} \cdot \mathrm{s}^{-1}$ by cyclic voltammetry (Figure $8 \mathrm{~A}$ ). The results illustrated quasi-reversible kinetics $[27,28] . \mathrm{E}_{\mathrm{pa}}$ and $\mathrm{E}_{\mathrm{pc}}$ 
shifted to more positive and more negative values, respectively (Figure 8B). Also, the $\Delta_{\varepsilon \varrho}$ increased with the increase in scan rate (Figure $8 \mathrm{C}$ ) while a linear relationship was obtained between the $\mathrm{I}_{\mathrm{p}}$ and square root (SQRT) of scan rate (Figure $8 \mathrm{D})$.

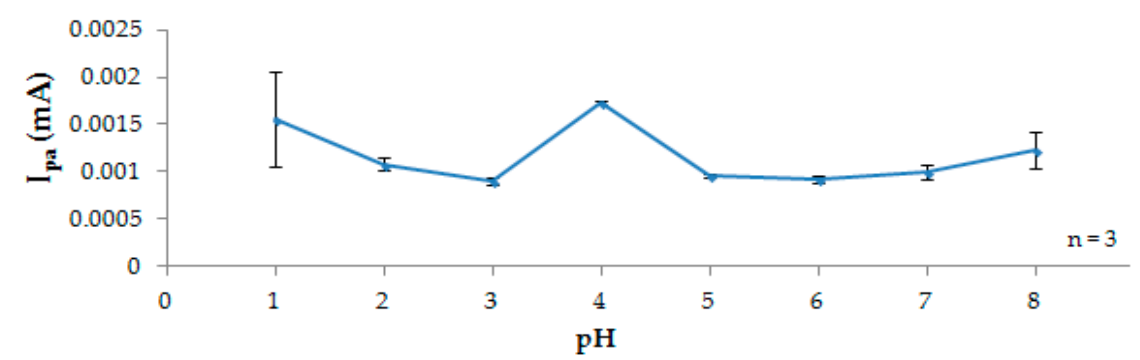

(A)

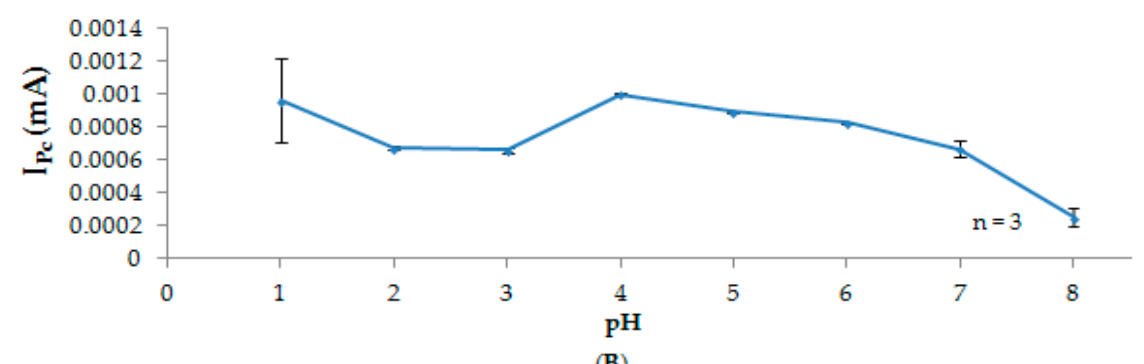

(B)

Figure 7. Effect of current as a function of $\mathrm{pH}$. (A) Anode current. (B) Cathode current. Not visible error bars: when the symbol size is larger than the error bar.

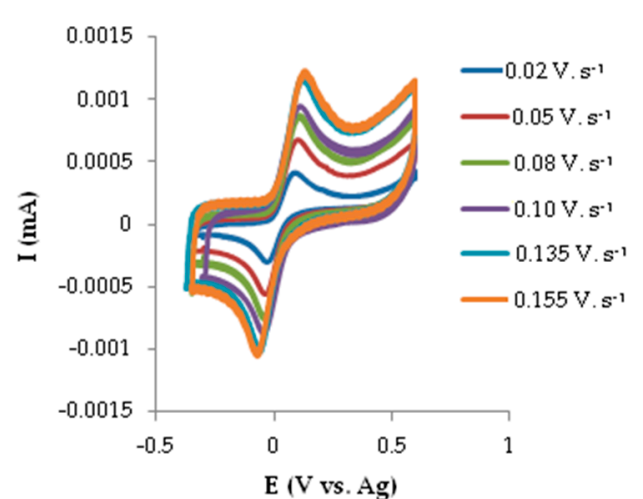

(A)

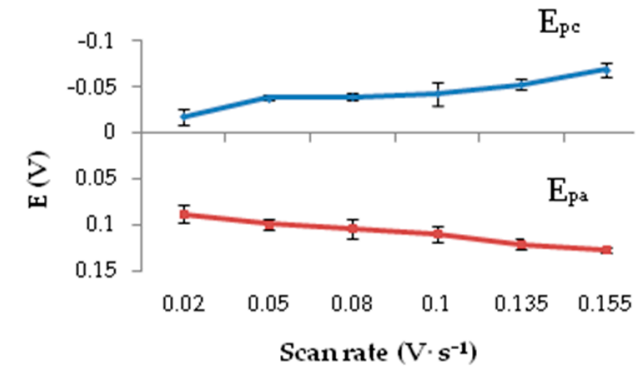

(B)

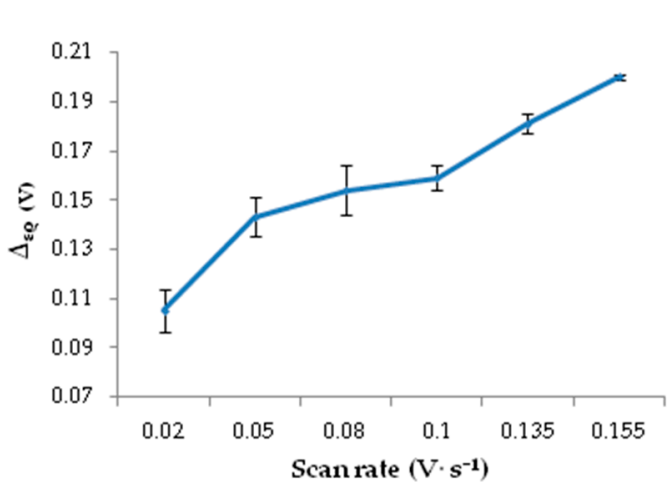

(C)

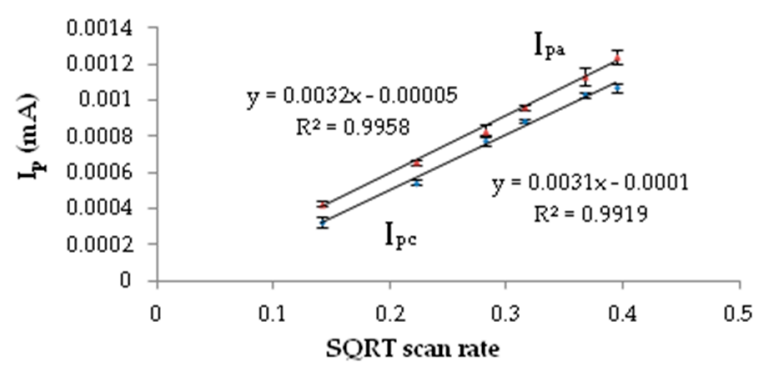

(D)

Figure 8. Scan rate investigations. (A) Cyclic voltammograms of DOPA from $0.02 \mathrm{~V} \cdot \mathrm{s}^{-1}$ to $0.155 \mathrm{~V} \cdot \mathrm{s}^{-1}$; (B) $\mathrm{E}_{\mathrm{Pc}_{\mathrm{c}}}$ and $\mathrm{E}_{\mathrm{pa}}$ variation with scan rate; (C) Variation of $\Delta_{\varepsilon \varrho}$ with scan rate and (D) Linear relationship of $\mathrm{I}_{\mathrm{pa}}$ and $\mathrm{I}_{\mathrm{pc}}$ with square root (SQRT) scan rate; Not visible error bars: when the symbol size is larger than the error bar. 
The transport mode of electroactive material towards the electrode surface is determined by the plot of logarithm current (Ip) versus logarithm scan rate (V). Slopes close to 1 suggest an adsorption process, below 0.5 a diffusion process and values between 0.5 and 1, a mixture of both diffusion and adsorption [27-29]. A linear relationship was found between the logarithm of $\mathrm{I}_{\mathrm{pa}}$ and $\mathrm{I}_{\mathrm{pc}}$ with the logarithm of scan rate (V), Equations (2) and (3), and the obtained slopes were 0.52 and 0.6 respectively, illustrating an adsorption-diffusion controlled process:

$$
\begin{aligned}
& \log I p a=0.52 \log V-2.5, \mathrm{R}^{2}=0.994 \\
& \log I p c=0.60 \log V-2.4, \mathrm{R}^{2}=0.995
\end{aligned}
$$

These particular findings are in a good agreement with previous published data of DOPA in solid electrodes [30-32]. As concluded, DOPA was oxidized electrochemically on the surface of a bare SPE into the corresponding dopaminoquinone, via the transfer of two electrons and two protons.

\subsection{Cyclic Voltammetry in the Presence of GSH}

Oxidation of DOPA $\left(2.5 \times 10^{-5} \mathrm{M}\right)$ in the presence of various GSH concentrations from $0 \mathrm{M}$ to $2.5 \times 10^{-4} \mathrm{M}$ was studied by cyclic voltammetry. As seen in Figure 9 , the voltammetric response of DOPA changed after the additions of GSH, illustrating the formation of a GSH-adduct and, as a consequence, the trapping of dopaminoquinone. $\mathrm{I}_{\mathrm{pc}}$ reduced with the increase of GSH, reaching almost an irreversible system at the highest GSH concentration $\left(2.5 \times 10^{-4} \mathrm{M}\right)$. The particular electrochemical response explained the consumption of dopaminoquinone through GSH conjugation. In addition, $\mathrm{I}_{\mathrm{pa}}$ increased and $\mathrm{E}_{\mathrm{pa}}$ shifted to more positive values, further implying the formation of a GSH-adduct metabolite, which was also electroactive.

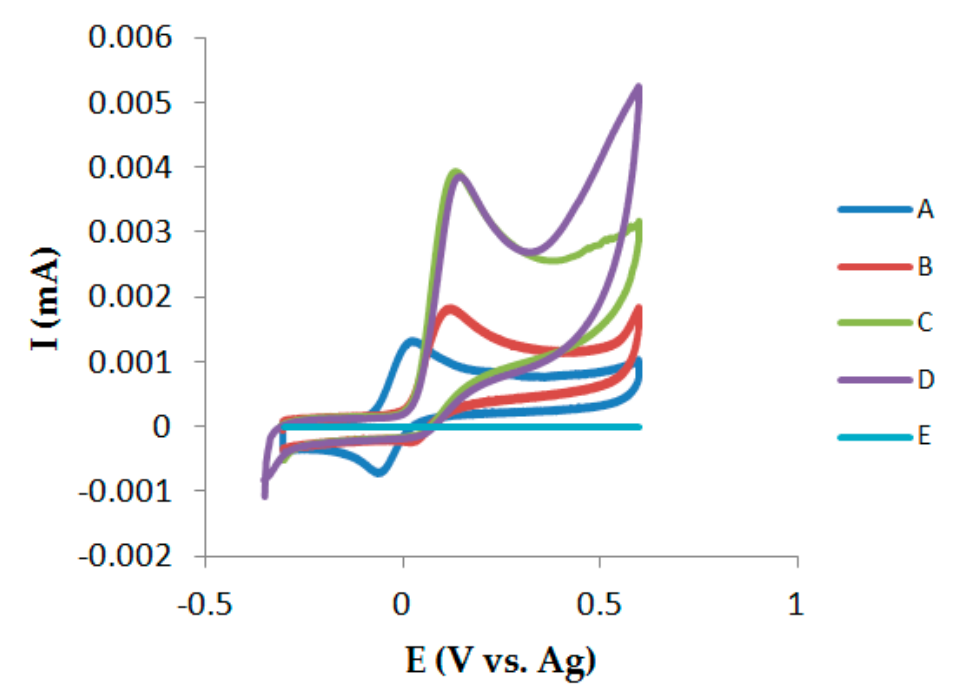

Figure 9. Cyclic voltammetry of DOPA $\left(2.5 \times 10^{-5} \mathrm{M}\right)$ as a function of GSH addition. (A) DOPA $\left(2.5 \times 10^{-5} \mathrm{M}\right)$. (B) In the presence of $5 \times 10^{-5} \mathrm{M} \mathrm{GSH}$. (C) In the presence of $1.24 \times 10^{-5} \mathrm{M}$ GSH. (D) In the presence of $2.5 \times 10^{-4} \mathrm{M} \mathrm{GSH}$. (E) GSH $\left(5 \times 10^{-5} \mathrm{M}\right)$.

\subsection{Potential Optimization}

The oxidative potential was optimized from $0.17 \mathrm{~V}$ to $0.52 \mathrm{~V}$, over a mass transport limit with increasing steps of $0.05 \mathrm{~V}$, as shown in Figure 10. The selection of potentials was based on the obtained voltammograms in Figure 9, in the presence of $5 \times 10^{-5} \mathrm{M}$ of GSH. The DOPA-GSH adduct $(m / z 459)$ was detectable at all potentials and the parent compound was depleted. The optimum potential was found to be $0.27 \mathrm{~V}$, since this is when higher yields were obtained, as indicated by the intensities from MS. 


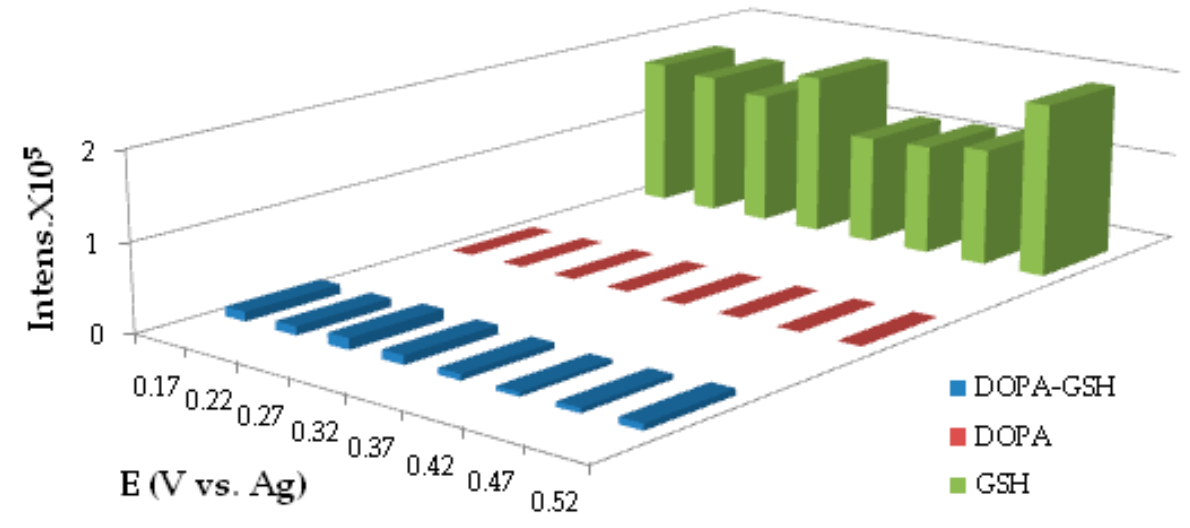

Figure 10. Potential optimization for DOPA electrochemical metabolism on a bare SPE.

\subsection{Exhaustive Electrolysis}

In order to generate higher metabolite yields, the optimized potential was held constant for $30 \mathrm{~min}$ over the same conditions. At the end of electrolysis, a brownish colour change was obtained in solution, which was not seen in potential optimization or during cyclic voltammetry. The brownish colour was attributed to a new metabolite with $m / z$ of 301 , which was found after prolonged electrolysis. As higher yields of dopaminoquinone were produced, this allowed further reactions to occur. Intermediates with dark colours have been reported in literature, as a part of DOPA phase 1 metabolism [22]. The glutathione disulphide (GSSG) was also obtained, confirming the ability of SPEs to generate multiple metabolites in extended times of electrolysis. The expected DOPA-GSH adduct was formed in lower intensities, compared to the new metabolite $(m / z$ of 301) (Figure 11).

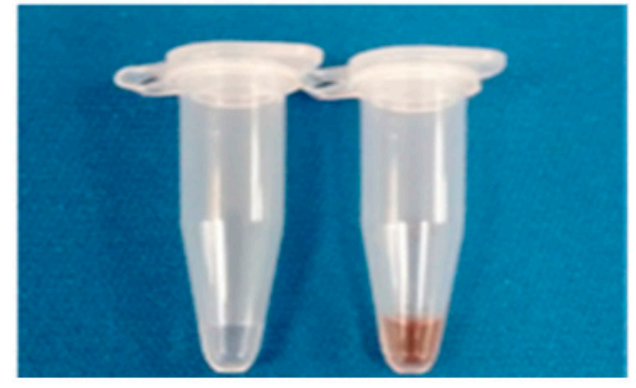

(A)

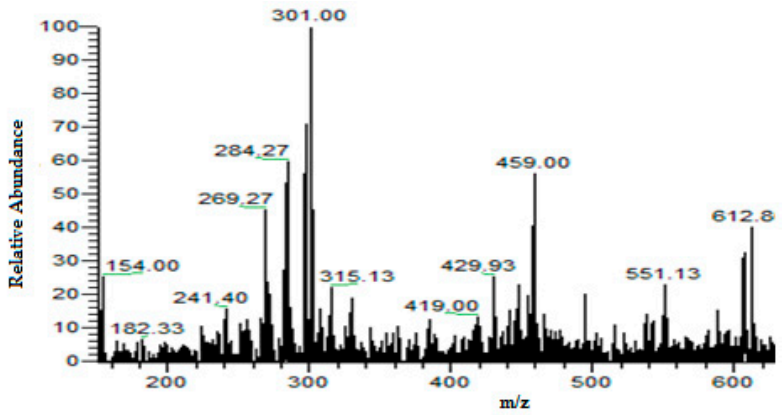

(B)

Figure 11. (A) Colour change after electrolysis; (B) Mass spectrum of DOPA electrochemical metabolism at $0.27 \mathrm{~V}$.

\subsection{Proposed Reaction Mechanism for Electrochemical Metabolism}

According to the obtained $\mathrm{m} / \mathrm{z}$, at the optimized potential of $0.27 \mathrm{~V}$, DOPA was oxidized via the transfer of two electrons and two protons into the reactive dopaminoquinone, Scheme 1. Subsequently, the phase I metabolite followed three main pathways leading to DOPA-GSH adduct, GSSG, and DOPA dimer. The first pathway involved the covalent conjugation of the electrogenerated dopaminoquinone with GSH, forming the expected phase II DOPA-GSH adduct $(m / z 459)$. In the second pathway, a series of electrochemical and chemical steps were taken, leading to a dimer $(m / z 301)$ with a brownish colour. In particular, dopaminoquinone was converted chemically into leucodopaminochrome via intramolecular cyclization, and subsequently electrochemically oxidised through the transfer of two electrons and two protons to the corresponding aminochrome. A polymerisation process between aminochrome and parent DOPA compound generated the phase I DOPA dimer metabolite. The side products were in an agreement with the relevant literature in electrochemical [31] and 
conventional metabolism $[22,33]$. Finally, the third pathway involved a catalytic process among the dopaminoquinone with GSH, causing the regeneration of the DOPA and the formation of the GSSG $(m / z 612)$.

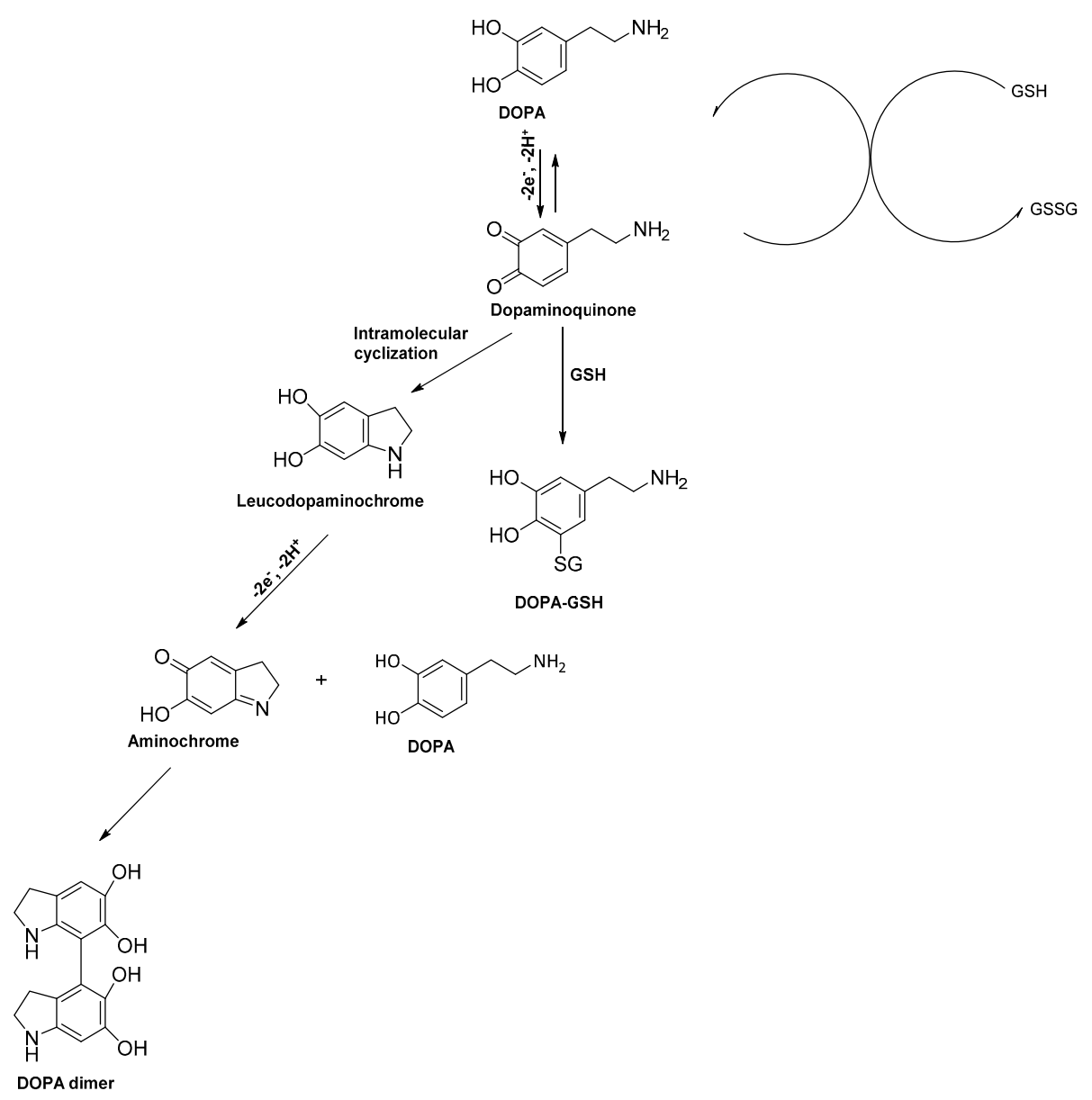

Scheme 1. Proposed reaction for the electrochemical metabolism of DOPA at $0.27 \mathrm{~V}$.

\section{Microfluidic Device with an SPE}

\subsection{Functionality of Chip}

The functionality of the chip in generating phase II GSH-adducts was initially investigated using APAP, considering its simple and well-studied electrochemical metabolism.

\subsubsection{Cyclic Voltammetry on Chip}

During validation studies, cyclic voltammetry was used to determine the potential range for CPE. Cyclic voltammograms of $\operatorname{APAP}\left(1 \times 10^{-3} \mathrm{M}\right)$ in $0.1 \mathrm{M}$ ammonium acetate were recorded on the chip at stop flow conditions and at various flow rates from $2.5 \mu \mathrm{L} \cdot \mathrm{min}^{-1}$ to $50 \mu \mathrm{L} \cdot \mathrm{min}^{-1}$. As shown in Figure 12, a well-defined quasi-reversible pair was obtained, illustrating the capability of chip to determine a potential range. Shifts in potentials have been obtained mainly in higher flow rates due to an enhanced material adsorption. 

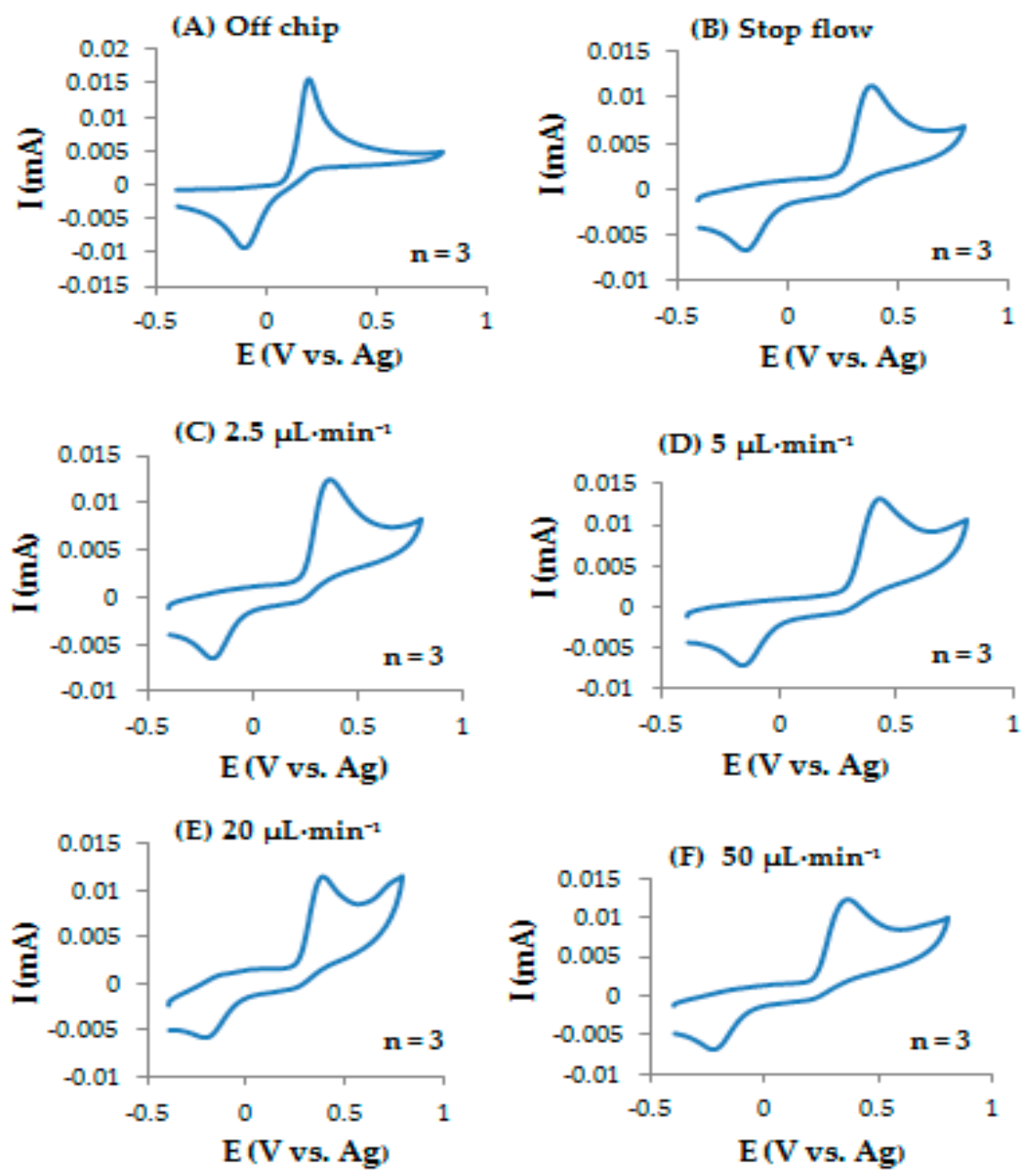

Figure 12. Cyclic voltammetry in the presence of APAP $\left(1 \times 10^{-3} \mathrm{M}\right)$. (A) Off chip; (B) Stop flow; (C) $2.5 \mu \mathrm{L} \cdot \min ^{-1}$; (D) $5 \mu \mathrm{L} \cdot \min ^{-1}$; (E) $20 \mu \mathrm{L} \cdot \mathrm{min}^{-1}$; (F) $50 \mu \mathrm{L} \cdot \min ^{-1}$.

\subsubsection{Electrolysis and GSH Conjugation on Chip}

The functionality of the chip in generating phase II GSH-adducts was investigated offline, using APAP as a drug probe. APAP $\left(2.5 \times 10^{-5} \mathrm{M}\right)$ in $0.1 \mathrm{M}$ ammonium acetate $(\mathrm{pH} 7.4)$ was infused into the surface of SPE and electrolysed for $6.4 \mathrm{~min}$, at $0.5 \mathrm{~V}$. The potential was not optimized; however, it was operated over a mass transport limit, since it was $0.1 \mathrm{~V}$ higher than the obtained oxidative peak in cyclic voltammetry. Subsequently, the effluent was collected and analysed by ESI/MS. The APAP-GSH adduct $(m / z 456.84)$ was generated successfully, as seen in Figure 13, confirming the complete mimicry of the phase I (dehydrogenation) and phase II (GSH conjugation) reactions.

\subsubsection{Online Coupling}

$\mathrm{CPE}$ in the potential range of $0.4 \mathrm{~V}$ to $0.75 \mathrm{~V}$ was recorded, in $0.05 \mathrm{~V}$ steps to determine the optimum potential for APAP-GSH formation. The conditions applied were the same as in offline coupling. The oxidation potential was $0.35 \mathrm{~V}$, as determined by cyclic voltammetry; however, the investigated potential range was at least $0.05 \mathrm{~V}$ higher to ensure minimum interference from kinetics. At the oxidative peak the electrochemical reaction is not completed yet and a strong competition is created between the electron transfer and mass transport. Thus, maximum metabolite yields can be obtained at higher potentials, where the electrochemical reaction leads gradually to depletion and the system is dominated by mass transport. As seen in Figure 14, the APAP-GSH adducts and GSSG were 
formed, suggesting the capability of the chip to mimic two metabolic pathways, simultaneously over flow conditions. The optimum potential for the APAP-GSH adducts was found to be $0.5 \mathrm{~V}$.

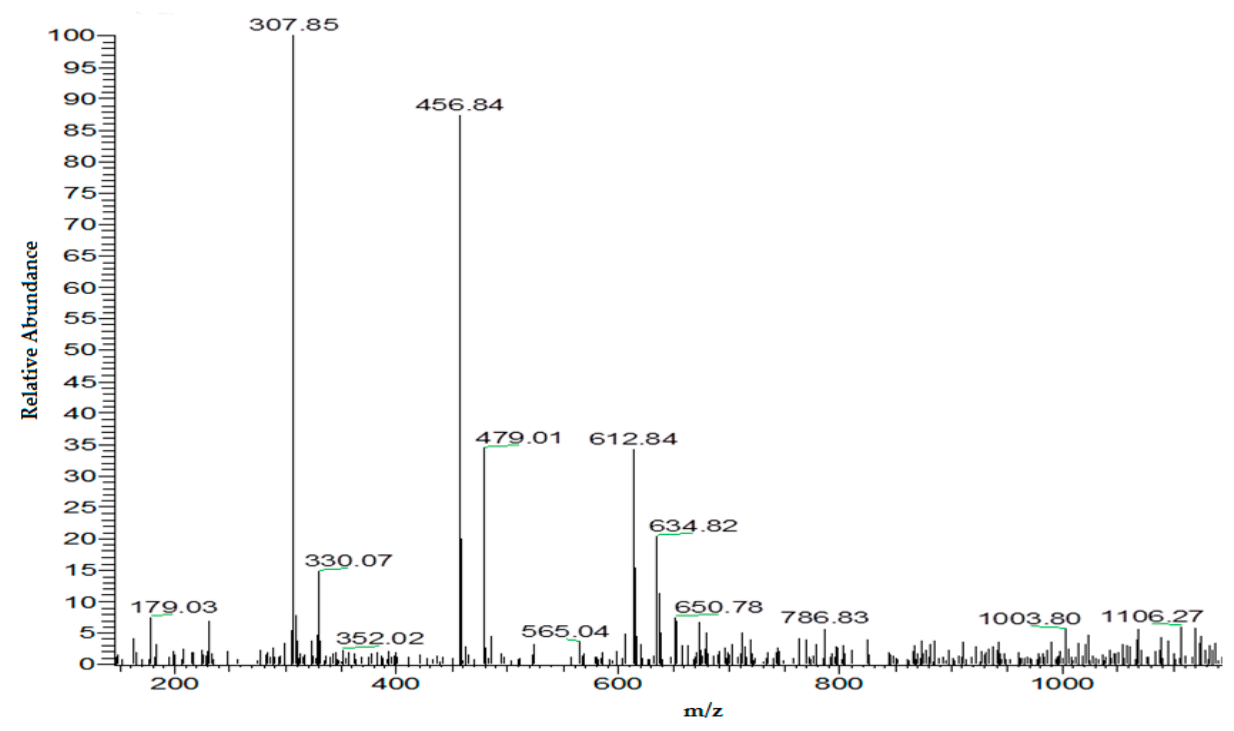

Figure 13. Microfluidic device coupled offline to mass spectrometry (MS).

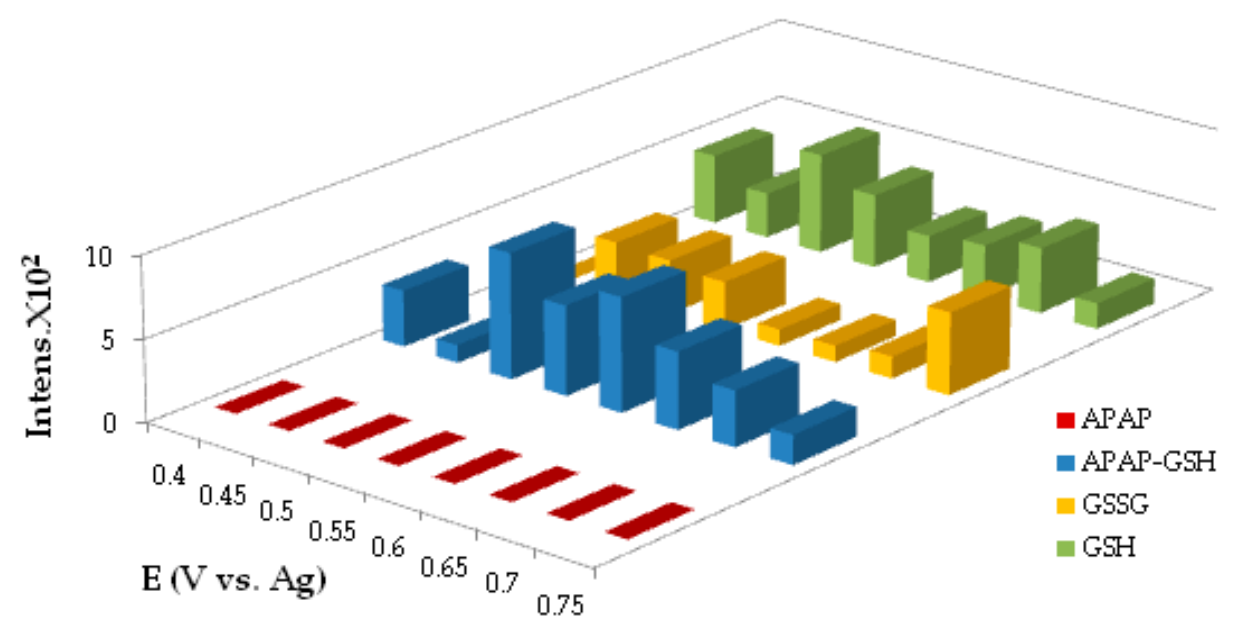

Figure 14. Potential optimizations of acetaminophen (APAP) electrochemical metabolism.

\subsubsection{Potential Optimization for the Generation of DOPA-GSH Adduct}

Experiments on an SPE confirmed the capability of the particular sensors to mimic multiple DOPA metabolites. The great instability of dopaminoquinone at $\mathrm{pH} 7.4$ permitted the generation of leucodopaminochrome. For this reason, the $\mathrm{pH}$ of DOPA solution was decreased to $\mathrm{pH} 7$, aiming for the total conversion of dopaminoquine into the required phase II adduct. In addition, the time of electrolysis was also reduced significantly to $6.4 \mathrm{~min}$ in order to prevent the dominance of leucodopaminochrome over GSH-adduct. As seen in Figure 15, the DOPA-GSH adduct $(m / z$ 459) was successfully formed at all potentials and the generation of the phase I dimer was avoided.

The maximum DOPA-GSH adduct formation was obtained at $0.37 \mathrm{~V}$. However, the optimum potential on the bare SPE was found to be at $0.27 \mathrm{~V}$. This observation is due to the surface chemistry having changed over flow conditions, leading to strong adsorption phenomena. The potential difference did not limit the functionality of the chip, since the DOPA-GSH was successfully generated and the aim of monitoring the phase II metabolism of DOPA was fulfilled. The obtained ion intensities for the DOPA-GSH adduct were increased from $0.17 \mathrm{~V}$ to $0.37 \mathrm{~V}$, and then decreased. Considering that 
SPEs have a limited potential application up to $1 \mathrm{~V}$, as the potentials were approaching the potential limit, the functionality and the electrochemical stability of the chip gradually started to decline. Additionally, the catalytic product of GSSG was also obtained as in the bare SPE; the spectra at the optimized potential of $0.37 \mathrm{~V}$ is shown in Figure 16. The ion intensities for the microfluidic device were lower when compared with earlier investigations on bare SPEs, due to the continuous sample dilution in a serpentine channel as well as adsorption effects.

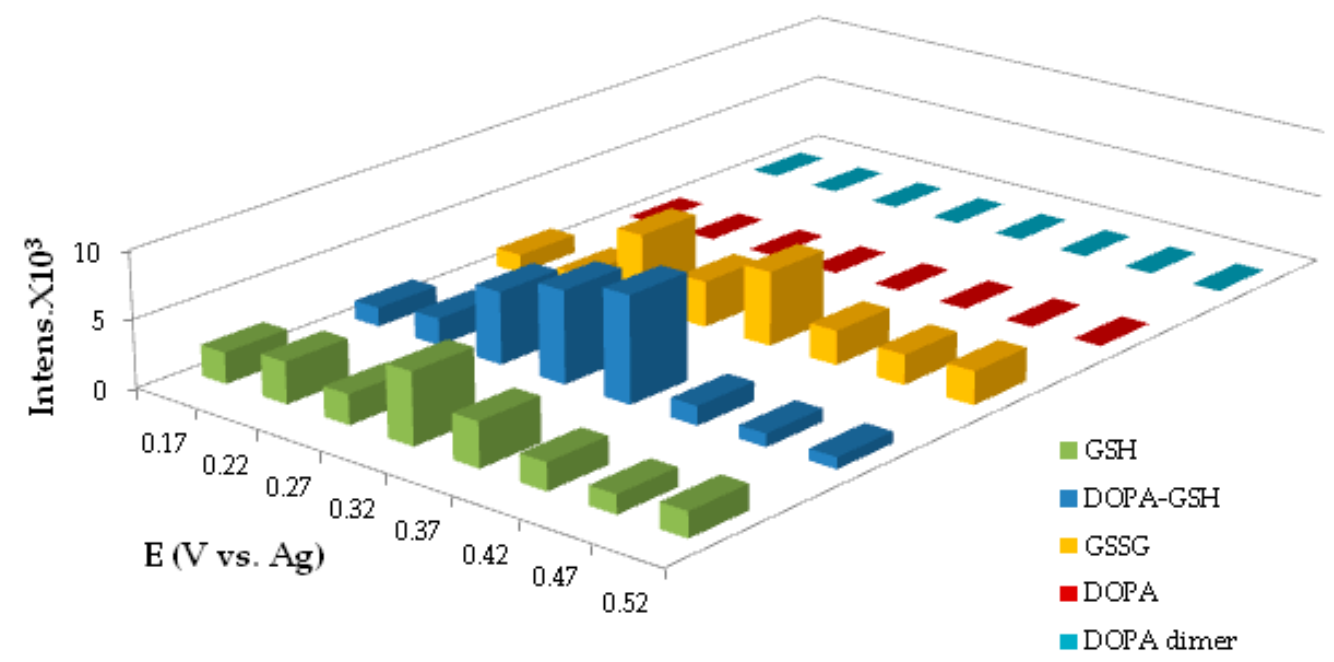

Figure 15. Potential optimization of DOPA electrochemical metabolism within the microfluidic device.

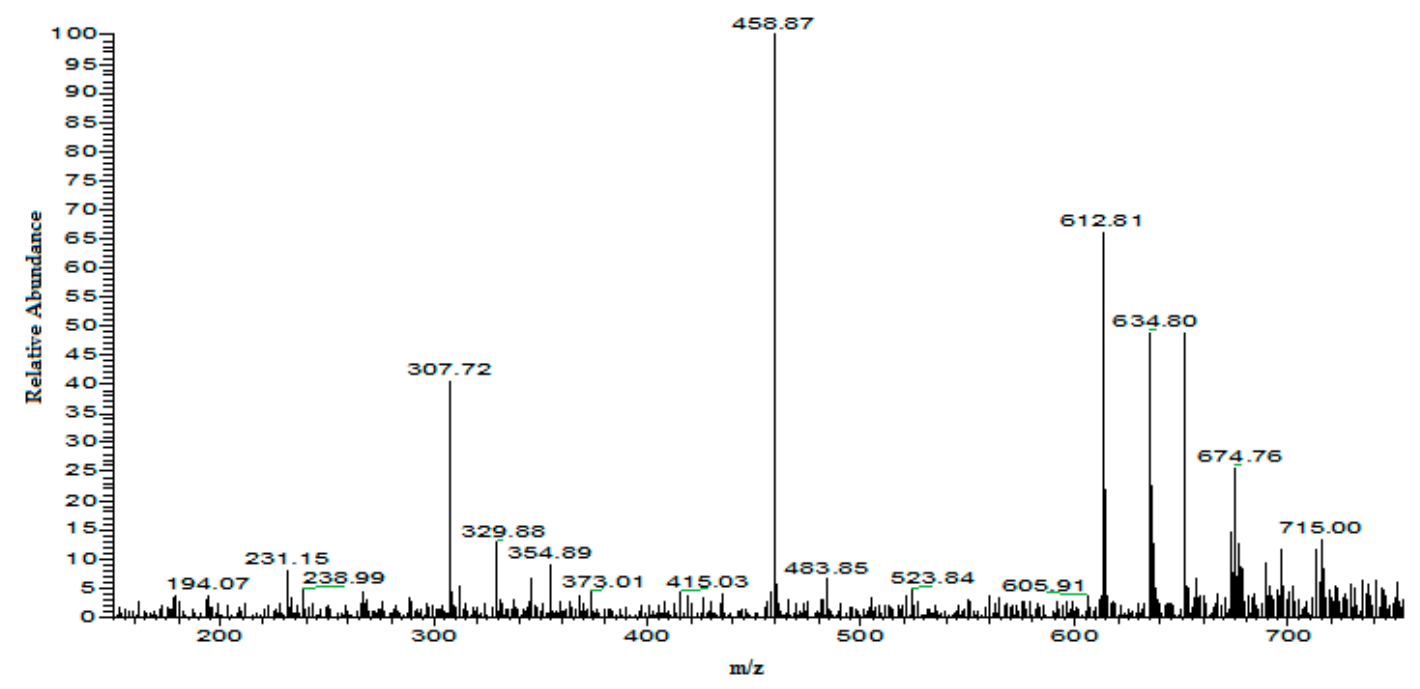

Figure 16. Mass spectra as obtained from the microfluidic device at the optimized potential of $0.37 \mathrm{~V}$.

\section{Conclusions}

A disposable microfluidic device with an SPE was developed and successfully mimicked the phase II metabolism. In particular, an SPE cell was combined with a serpentine channel that allowed the generation and detoxification of dopaminoquinone, respectively. A metabolic profile was obtained in less than 10 min without the use of any tedious cleaning processes. The total cost for each chip was only 5 GBP, providing a cheaper alternative to the current in vitro studies. The proposed chip has the potential to be used as a primary screening tool in pharmaceutical and clinical research, and thereby complement the current methodologies.

Acknowledgments: This study has not received any form of financial support. 
Author Contributions: R.V. designed and performed the experiments, the data analysis, created and edited the manuscript and illustration. M.M.N.E. and N.J.B. designed and fabricated the chip. K.J.W. contributed to the study concept and design, offering supervision together with technical and administrative support throughout the entire duration of project.

Conflicts of Interest: The authors declare no conflict of interest.

\section{References}

1. Xu, C.; Li, Y.T.C.; Kong, A.N.T. Induction of phase I, II and III drug metabolism/transport by xenobiotics. Arch. Pharm. Res. 2005, 28, 249-268. [CrossRef] [PubMed]

2. Iyanagi, T. Molecular mechanism of phase I and phase II drug-metabolizing enzymes: Implications for detoxification. Int. Rev. Cytol. 2007, 260, 35-112. [PubMed]

3. Jancova, P.; Anzenbacker, P.; Anzenbacherova, E. Phase II metabolizing enzymes. Biomed. Pap. 2010, 154, 103-116. [CrossRef]

4. Hayes, J.D.; Flanagan, J.U.; Jowsey, I.R. Glutathione transferases. Annu. Rev. Pharmacol. Toxicol. 2005, 45, 51-88. [CrossRef] [PubMed]

5. Alfafara, C.G.; Kanda, A.; Shioi, T.; Shimizu, H.; Shioya, S.; Suga, K. Effect of amino-acids on glutathione production by sacharromyces-cerevisiaie. Appl. Microbiol. Biotechnol. 1992, 36, 538-540. [CrossRef]

6. Rajasekaran, M.; Abirami, S.; Chen, C. Effects of Single Nucleotide Polymorphisms on Human N-Acetyltransferase 2 Structure and Dynamics by Molecular Dynamics Simulation. PLoS. ONE 2011, 6, 1-12. [CrossRef] [PubMed]

7. Srivastava, A.; Maggs, J.L.; Antoine, D.J.; Williams, D.P.; Smith, D.A.; Park, B.K. Role of reactive metabolites in drug-induced hepatotoxicity. In Adverse Drug Reactions; Springer: Heidelberg, Germany, 2010; pp. 165-194.

8. Lohmann, W.; Karst, U. Generation and identification of reactive metabolites by electrochemistry and immobilized enzymes coupled on-line to liquid chromatography/mass spectrometry. Anal. Chem. 2007, 79, 6831-6839. [CrossRef] [PubMed]

9. Baumann, A.; Karst, U. Online electrochemistry/mass spectrometry in drug metabolism studies: Principles and applications. Expert Opin. Drug Metab. Toxicol. 2010, 6, 715-731.

10. Van Leeuwen, S.M.; Blankert, B.; Kauffmann, J.M.; Karst, U. Prediction of clozapine metabolism by on-line electrochemistry/liquid chromatography/mass spectrometry. Anal. Bioanal. Chem. 2005, 382, 742-750. [CrossRef] [PubMed]

11. Plattner, S.; Pitter, F.; Brouwer, H.J.; Oberacher, H. Formation and Characterization of Covalent Guanosine Adducts with Electrochemistry-Liquid Chromatography-Mass Spectrometry. J. Chromatogr. B Analyt. Technol. Biomed. Life Sci. 2012, 883-884, 198-2014. [CrossRef] [PubMed]

12. Lohmann, W.; Hayen, H.; Karst, U. Covalent Protein Modification by Reactive Drug Metabolites Using Online Electrochemistry/Liquid Chromatography/Mass Spectrometry. Anal. Chem. 2008, 80, 9714-9719. [CrossRef] [PubMed]

13. Regino, M.C.S; Brajiter-Toth, A. An electrochemical cell for on-line electrochemistry/mass spectrometry. Anal. Chem. 1997, 69, 5067-5072. [CrossRef]

14. Getek, T.A.; Korfmacher, W.A.; Mcrae, T.A.; Hinson, J.A. Utility of solution electrochemistry mass spectrometry for investigating the formation and detection of biologically important conjugates of acetaminophen. J. Chromatogr. A 1989, 479, 245-256. [CrossRef]

15. Lohmann, W.; Karst, U. Simulation of detoxification of paracetamol using on-line electrochemistry/liquid chromatography/mass spectrometry. Anal. Bioanal. Chem. 2006, 386, 1701-1708. [CrossRef] [PubMed]

16. Van den Brink, F.T.G.; Buter, L.; Odjik, M.; Olthuis, W.; Karst, U.; van den Berg, A. Mass spectrometric detection of short-lived drug metabolites generated in an electrochemical microfluidic chip. Anal. Chem. 2015, 87, 1527-1535. [CrossRef] [PubMed]

17. Roussel, C.; Dayon, L.; Lion, L.; Rohner, T.C.; Josserand, J.; Ropssier, J.S.; Jensen, H.; Girault, H.H. Generation of Mass Tags by the Inherent Electrochemistry of Electrospray for Protein Mass Spectrometry. J. Am. Soc. Mass Spectrom. 2004, 15, 1767-1779. [CrossRef] [PubMed]

18. Miserere, S.; Ledru, S.; Ruille, N.; Criveau, S.; Boujtita, M.; Bedioui, F. Biocompatible carbon-based screen-printed electrodes for the electrochemical detection of nitric oxide. Electrochem. Commun. 2006, 8, 238-244. [CrossRef] 
19. Mistry, K.K.; Layek, K.; Mahapatra, A.; RoyChaudhurib, C.; Sahab, H. A review on amperometric-type immunosensors based on screen-printed electrodes. Analyst 2014, 139, 2289-2311. [CrossRef] [PubMed]

20. Khaled, E.; Hassan, H.N.A.; Habib, I.H.I.; Metelka, R. Chitosan modified screen-printed carbon electrode for sensitive analysis of heavy metals. Int. J. Electrochem. Sci. 2010, 5, 158-167.

21. Kauffmann, J.M.; Antwerpen, P.V.; Sarakbi, A.; Feier, B.; Tarik, S.; Aydogmus, Z. Utility of Screen Printed Electrodes for in Vitro Metabolic Stability Assays: Application to Acetaminophen and its Thioconjugates. Electroanalysis 2011, 23, 2643-2650. [CrossRef]

22. Monoz, P.; Melendez, C.; Paris, I.; Sequra-Aquilar, J. Molecular and neurochemical mechanism dopamine oxidation to 0-quinone in Parkinson disease pathogenesis. In Toxicity and Autophage in Neurodegenerative Disorders; Springer: Basel, Switzerland, 2015; pp. 205-223.

23. Eklund, J.C.; Alan, B.M.; Alden, J.A.; Gompton, R.G. Perspectives in modern voltammetry: Basic Concepts and Mechanistic Analysis. Adv. Phys. Org. Chem. 1999, 2, 1-120.

24. Mahanthesha, K.R.; Kumara-Swamy, B.E.; Vasantakumar-Pai, K.; Chandra, U.; Sherigara, B.S. Cyclic Voltammetric Investigations of Dopamine at Alizarin Modified Carbon Paste Electrode. Int. J. Electrochem. Sci. 2010, 5, 1962-1971.

25. Nematollahi, D.; Shayani-Jam, H.; Alimoradi, M.; Niroomand, S. Electrochemical oxidation of acetaminophen in aqueous solutions: Kinetic evaluation of hydrolysis, hydroxylation and dimerization processes. Electrochim. Acta 2009, 54, 7407-7515. [CrossRef]

26. Joseph, B.; Justice, J.R. Introduction to in Vivo Voltammetry. In Voltammetry in the Neurosciences; Adams, R.N., Justice, J.B., Eds.; Humana Press: New York, NY, USA, 1987; pp. 15-17.

27. Bagheri, A.; Hosseini, H. Electrochemistry of raloxifene on a glassy carbon electrode and its determination in pharmaceutical formulation and human plasma. Bioelectrochemistry 2012, 88, 164-170. [CrossRef] [PubMed]

28. Hasan, M.M.; Hossain, M.E.; Mamum, M.A.; Ehsan, M.Q. Study of redox behavior of Cd(II) and interaction of Cd(II) with proline in the aqueous medium using cyclic voltammetry. J Saud. Chem. Soc. 2012, 16, 145-151.

29. Ndangli, P.M.; Jijana, A.N.; Olowu, R.N.; Mailu, S.N.; Ngece, F.R.; Williams, A.; Waryo, T.T.; Baker, P.G.L. Impedimetric Response of a Label-Free Genosensor Prepared on a 3-Mercaptoprionic Acid Capped Gallium Selenide Nanocrystal Modified Gold Electrode. Int. J. Electrochem. 2011, 6, 1438-1453.

30. Ahuja, S.; Jespersen, N. Modern Instrumental Analysis; Elsevier: Kidlington, UK, 2006.

31. Ke, N.J.; Lu, S.H.; Cheng, S.H. A strategy for the determination of dopamine at a bare glassy carbon electrode: p-Phenylenediamine as a nucleophile. Electrochem. Commun. 2006, 8, 1514-1520. [CrossRef]

32. Liu, C.Y.; Liu, Z.Y.; Peng, R.; Zhong, Z.C. Quasireversible Process of Dopamine on Copper-Nickel Hydroxide Composite/Nitrogen Doped Graphene/Nafion Modified GCE and Its Electrochemical Application. J. Anal. Methods Chem. 2014, 2014, 1-7. [CrossRef] [PubMed]

33. Spina, M.B.; Cohen, G. Dopamine turnover and glutathione oxidation: Implications for Parkinson disease. Proc. Natl. Acad. Sci. USA 1989, 86, 1398-1400. [CrossRef] [PubMed]

(C) 2016 by the authors; licensee MDPI, Basel, Switzerland. This article is an open access article distributed under the terms and conditions of the Creative Commons Attribution (CC-BY) license (http://creativecommons.org/licenses/by/4.0/). 